\title{
26 Research Square \\ Detecting Bone Lesions in The Emergency Room With Medical Infrared Thermography
}

Wally auf der Strasse ( $\nabla$ wallystrasse@hotmail.com )

CPGEI - Universidade Tecnológica Federal do Paraná

Daniel Prado Campos

CPGEI - Universidade Tecnológica Federal do Paraná

Celso Júnio Aguiar Mendonça

CPGEI - Universidade Tecnológica Federal do Paraná

Jamil Faissal Soni

PPGCS - Pontifícia Universidade Católica do Paraná

Joaquim Mendes

University of Porto

Percy Nohama

PPGTS - Pontifícia Universidade Católica do Paraná

\section{Research Article}

Keywords: Infrared thermal imaging, bone fracture, screening temperature, bone lesion identification, diagnostic tool, emergence room

Posted Date: November 10th, 2021

DOI: https://doi.org/10.21203/rs.3.rs-1054776/v1

License: (c) (1) This work is licensed under a Creative Commons Attribution 4.0 International License.

Read Full License 


\section{Abstract}

Introduction: Low to high-energy impact trauma may cause from small fissures up to extended bone losses, which can be classified as closed or opened injuries (when they are visible at a naked eye).

Objective: The aim of this study was to investigate the feasibility of clinical diagnosis of bone trauma through medical infrared thermography, in a hospital emergency room.

Methods: Forty-five patients with suspected diagnosis of bone fracture were evaluated by means of medical infrared images, and the data correlated to the gold standard radiographic images, in the anteroposterior, lateral, and oblique views, at the orthopedic emergency department. The control group consisted of thermal images of the contralateral reference limb of the volunteers themselves. Data were acquired with a medical grade infrared camera in the regions of interest (ROIs) of leg, hand, forearm, clavicle, foot, and ankle.

Results: In all patients evaluated with a diagnosis of bone fracture, the mean temperature of the affected limb showed a positive difference greater than $0.9^{\circ} \mathrm{C}$ (towards the contralateral), indicating the exact location of the bone trauma according, while the areas diagnosed with reduced blood supply, showed a mean temperature with a negative variation.

Conclusion: Clinical evaluation using infrared imaging indicates a high applicability potential as a tool to support quick diagnosis of bone fractures in patients with acute orthopedic trauma in an emergency medical setting. The thermal results showed important physiological data related to vascularization of the bone fracture and areas adjacent to the trauma well correlated to radiographic examinations.

\section{Background}

Bone fractures are considered common orthopedic trauma in emergency room departments in a hospital environment, they can result from high-energy trauma such as car accidents, falls from heights, injurie due to shot guns, or otherwise from low-energy trauma caused by sports injuries or bone diseases such as osteoporosis, and bone tumor [1]. Traumas such as cracks in bone tissue caused by excessive exercise or repeated bone impacts, are called stress fractures [2]. Closed fractures tend to cause an increase in temperature at the bone lesion site. These thermal changes are originated by increased blood flow around the lesion, as observed at the fracture site, already highlighted by previous studies [3]. However, the temperature may also decrease, depending on the severity of the injury, if the regenerative process stops or if blood flow reduces [4].

In the initial screening of injuries performed by orthopedic surgeons, the gold standard is the diagnostic evaluation through medical X-ray imaging. However, many injuries are not apparent in the first weeks of bone trauma, such as stress fractures, which only show traces of damage to the cortical bone, one to two weeks after the traumatic event $[5,6]$. Yet, another difficult fracture to diagnose, is radial bone fracture in pediatric patients, where the X-ray examination needs to be repeated after one or two weeks of trauma for 
confirmation [7]. In the trauma emergency room, novel technologies point to the importance of supporting the diagnosis of the injury and involvement of tendons and soft tissues adjacent to the fracture site.

Just after the fracture episode, there is a vascular interruption, and an immediate inflammatory response at the trauma site close to the injury [8]. The acute inflammatory process causes an increase in the cytokines proteins that accumulate at the site of injury, which increases the metabolism and the temperature of surrounding tissues [3]. Subsequently, there is a greater recruitment of mesenchymal stem cells and subsequent differentiation into chondrocytes, followed by vascular ingrowth and intensification of neo-angiogenesis. The cells stimulate the growth of blood vessels in the periosteum, the production of cartilage, and increase the action of osteoblastic cells to initiate bone repair [9]. The inflammatory process and changes in blood perfusion causes a change in the thermal pattern visible at the skin through medical infrared thermography (IRT) $[4,8]$. In view of these aspects, the use of IRT has been increasingly investigated, highlighting diagnostic images of trauma in the extremities of upper limbs in pediatric patients [7]. Likewise, Vardasca investigated the temperature distribution symmetry patterns of the upper and lower extremities, by using IRT to discriminate and establish thermal profile in healthy people for correlation with injuries [10].

Di Benedetto et al. observed regions with decreased temperatures in non-severe traumatic injuries [11]. Likewise, other investigations use IRT in patients diagnosed with bone nonunion in bone elongation process $[12,13]$, or in the assessment of focal thermal changes in vertebrae with increased bone resorption after drug administration of bisphosphonates in the treatment of osteoporosis of the lumbar spine [14].

The authors [15] also performed IRT in a trauma department, at an emergency unit of a Spanish hospital. A total of 133 radiographs of trauma in forearm bones were correlated with thermal images acquired in pediatric patients and the results demonstrated a sensitivity of $91 \%$ and specificity of $81 \%$ in the examination. Thus, the authors also suggest IRT as a promising diagnostic method for identifying bone fractures.

The technological advances achieved by infrared cameras in recent years have resulted in an improved diagnostic capability and greater confidence, which has increased the sensitivity and spread the method's employability in various clinical specialties $[16,17]$ and having found wide acceptance in the medical community [18]. Efficiency, combined with the lowest comparative financial cost of the magnetic resonance imaging (MRI) and computer tomography (CT) technologies, combined with the safety of image acquisition as it does not emit ionizing radiation, makes thermography an auxiliary tool in diagnostic imaging medicine [16].

However, the applicability of IRT is limited for monitoring fractures in apparent bones, which are closer to the skin, otherwise for bones covered with a large layer of muscle tissue, such as the femur bone, it is not possible to perform a diagnostic by thermography. 
Given the above, this study investigated the feasibility of using IRT in the immediate assessment of acute fractures in adult patients. For this purpose, images were obtained from apparent bones of forearm, hands, clavicle, leg, ankle, and feet that were analyzed and correlated with conventional X-ray images, in a hospital emergency department, as to support the clinical diagnosis of bone trauma.

\section{Results}

In total, 45 diagnostics of bone fractures were evaluated using thermographic images, 8 in the leg bones, 14 in the hands, 10 in the forearm bones, 4 in the trunk, 6 in the feet and 3 in the ankle, as shown in Figure 2.

Regarding the 8 legs fracture diagnosis, thermographic images of the contralateral limb were not obtained in two patients with tibial fractures, as the evaluated patients entered the hospital on a medical rescue ambulance stretcher, which prevented the removal of the clothing that covered the contralateral leg. Likewise, in seven thermographic evaluations in hand trauma, seven in the forearm, two fractures in the feet and one in the ankle region, the same problem occurred. In addition, most of them present strong painful symptoms, thus it was avoided any no compulsory manipulations of the body.

In the analysis of the mean temperatures obtained from thermal images of the eight volunteers acquired in the lower limbs, the data showed that in the fracture which occurred in the proximal tibial (plateau), the temperature immediately besides the fracture was higher when comparing to the distal portions and fibula. It was highlighted in the observations of the thermal images that in the case of double diaphyseal bone fracture (tibia and fibula), the thermal data denoted an important comparative temperature change, with a mean difference of $4.5^{\circ} \mathrm{C}$ when compared to the contralateral limb.

The difference between the average temperature in the affected limb towards the contralateral ranges from $1.4{ }^{\circ} \mathrm{C}$ to $3.4^{\circ} \mathrm{C}$ (volunteer 4 , at tibial plateau), according to data shown in Figure 3 and corresponding $\mathrm{X}$-ray and visible images, Figure 4.

The analysis of the images involving fractures of the segment of the hands showed differences in the mean temperatures according to the time of occurrence of the trauma. Regarding the metacarpal and carpal bones (volunteers 10,16, 18 and 21), higher mean temperatures were measured in the assessment of acute trauma; however, in the assessment of metacarpal fracture three weeks after the occurrence, the data demonstrated thermal normalization, showing equal temperatures $\left(28.3^{\circ} \mathrm{C}\right)$ in both limbs. In evaluated traumas of the scaphoid bone (volunteers 9 and 12), considered fractures that require longer healing time due to its joint mobility, the mean temperature was higher than $33.0^{\circ} \mathrm{C}$.

In phalanges trauma assessments and according to their location in the portion of the fractured finger, the average temperature range showed great thermal variability, with values between $28.7^{\circ} \mathrm{C}$ and $35.0^{\circ} \mathrm{C}$, the highest value was in proximal phalangeal fractures. 
Patient number 17 entered the emergency room with an open fracture and amputation of the $4^{\text {th }}$ proximal finger of the right hand. Due to the wound and lost of tissue at the injury site, the hand has a lower mean temperature than the contralateral one.

On the other hand, a large thermal change was observed in the injury of volunteer 22 , due to a total fracture of the medial phalanx and tearing of the tendon of the fourth finger, requiring reconstructive surgery, as shown in Figure 5 and the corresponding X-ray and visible images, Figure 6.

In the ten forearm fractures, the most common trauma was the distal portion of the radius bone. All evaluated volunteers entered the hospital after a fall from a level or a car accident, with intense pain symptoms. In some patients, it was not possible to obtain a thermal image of the contralateral limb due to the difficulty of removing the cloths. Mean temperature in the affected forearm ranged from 33.9 to $35.7^{\circ} \mathrm{C}$. Differences in mean temperature compared to the healthy limb were higher than $1.0^{\circ} \mathrm{C}$, according to data shown in Figure 7 and the corresponding X-ray and visible images, Figure 8.

All the trunk fractures were provoked by fall and occurred on the right side of the body hemisphere. They were diagnosed in the clavicle bone, with mean temperature values above $35.0^{\circ} \mathrm{C}$. Volunteer $34 \mathrm{had}$ a fracture with displacement, with strong painful symptoms and bone prominence on clinical palpation, according to data shown in Figure 9 and the corresponding X-ray and visible images, Figure 10.

The evaluated traumas in feet occurred mainly in the bone portions of the toes. For two volunteers, there was no possibility to acquire comparative images of the contralateral limb.

Volunteer 40 had an open fracture of the big toe, in the distal portion of the phalanx, with more accentuated thermal change $\left(33.2^{\circ} \mathrm{C}\right)$, volunteer 42 also had a Lisfranc fracture, in the middle foot, with rupture of the three tarsometatarsal joints, exhibiting high temperature $\left(34.1^{\circ} \mathrm{C}\right)$. Patient number 41 , on the other hand, denoted a very cold temperature in the distal portion of the bone phalanx of the third finger $\left(20.1^{\circ} \mathrm{C}\right)$, as the diagnostic evaluation was carried out three days after the occurrence of the trauma, as shown in Figure 11 and the respective radiographs and visible images, in Figure 12.

The thermographic images obtained from the ankle fractures were evaluated in the medial malleolus of volunteer 43 and in the lateral malleolus of the fibula in volunteer 44 . Bone fracture in the pylon region of the tibia distal portion presented by volunteer 45 , showed a high thermal difference $\left(7.9^{\circ} \mathrm{C}\right)$ at the trauma focal point, compatible with the radiologic images and strong painful symptoms expressed by the volunteer, Figure 13 and the corresponding X-ray and visible images, Figure 14.

\section{Discussion}

Acute bone fractures present hyperthermia and intense inflammatory response within 24 hours after trauma [19], providing a predictive indication of bone injury by means of the infrared images, due to the relevant increasing in the measured temperature in the lesion focal point, and on adjacent areas of the assessed body segment [7]. The detection of the highest temperature area favors the targeting of 
radiographic image acquisition. Indeed, the thermal pattern reflects the underlying physiology of the affected limb by increasing / decreasing the peripheral blood flow regulated by the autonomic nervous system $[20,21]$.

Regarding the analysis of the 10 thermal images of the volunteers investigated with forearm fractures, it was observed that the temperature of the radius and ulna showed temperature differences between 1.0 and $2.7^{\circ} \mathrm{C}$, denoting thermal changes compatible with bone fracture diagnostic. These data were corroborated by the findings of the authors [22], who investigated changes in temperature on the day of trauma and during the healing of the fracture in the forearm in a clinical follow-up of nineteen pediatric patients. The authors observed differences of up to $2.8^{\circ} \mathrm{C}$ in the first week of the fracture, as measured in our study for volunteer 24 with radiographic diagnostics of distal radius fracture.

The study [23] developed by Charters, A. also demonstrated that the use of IRT was useful in the detection of fractures of the radius and distal ulna in pulses of sixty-seven children. The results analysis indicated that from a total of 34 thermal images 31 of them confirmed the fracture diagnostic performed by $\mathrm{X}$-ray imaging. They presented a temperature difference at the fracture focal point higher than $1{ }^{\circ} \mathrm{C}$ when compared to the control limb used as thermal reference. Thus, showing the feasibility of thermal imaging as a diagnostic tool in children in the emergency room environment, with diagnostic sensitivity of $96.8 \%$ when compared to X-rays, and up to $96.7 \%$ if compared to clinical examination.

In view of the investigations in pediatric patients, the results evaluated in 105 children with wrist fractures stand out that bone trauma is often not visible in the first radiographic images. The authors [8] evaluated the patients through infrared diagnostic images, with screening in diagnoses of sprain and bone fracture, and proposed an algorithm for differentiating the two diagnoses, orthopedic trauma as a screening or adjunct to clinical diagnosis in a hospital setting.

In the unique study with adult volunteers evaluating forearm bone fractures, the researchers [3] investigated fractures in the distal portion of radius bone in the orthopedic emergency environment, with imaging on the trauma day and subsequent follow-up evaluations. The results also showed thermal differences greater than $0.6^{\circ} \mathrm{C}$, compared to the reference contralateral limb. The authors also pointed out the feasibility of thermographic examination in the orthopedics clinical practice, as an excellent method of monitoring the evolution of the bone healing process, strongly corroborating our results in the evaluation of forearm traumas and the diagnostic.

Regarding the thermal responses verified in hand bones, the results showed differences in the mean temperature measured in the phalanges, in the diagnosis of bone fracture with amputation of the distal portion of the fourth finger $\left(34.1^{\circ} \mathrm{C}\right)$, verified in volunteer number 17 , and increase of mean temperature in a scaphoid bone fracture $\left(34.8^{\circ} \mathrm{C}\right)$, in volunteer 12 . The measured temperatures had denoted to be elevated for this body segment, considering that body extremities tend to be lower due to the decrease in vascularization. 
Infrared images of the hand were evaluated by U. Snekhalatha et al. [24] to detect rheumatoid arthritis, based on the heat distribution. In healthy people, automatic segmentation of abnormal regions of the hand of patients with arthritis, was performed using fuzzy algorithm and expectation maximization (EM) algorithm.

The results showed a $0.96{ }^{\circ} \mathrm{C}$ increase on temperature in the hand region of volunteers with arthritis compared to healthy volunteers. In the present study, 14 patients with hand fractures diagnostics show an increase of more than $1{ }^{\circ} \mathrm{C}$ in mean temperature difference to the contralateral. Depending on the injury severity, an eventual displacement or rotation of the bone fragments may happen, as verified in volunteer 22, in the fracture diagnostics of the proximal phalanx, thermal differences were even higher $\left(7.7^{\circ} \mathrm{C}\right)$.

The researchers [25] also carried out investigations of infrared thermal imaging in hands and upper limbs. The results strengthen the applicability of infrared imaging exams, presenting it as a safe and innocuous technology, providing additional data to be added to the immediate diagnostics and the patient's clinical follow-up.

In the same sense, the researchers [10] investigate thermal symmetry of the body segments of arms, hands, legs, and feet in thirty-nine adult male volunteers. The results showed that temperature asymmetry can be significant in musculoskeletal disorders, with unilateral manifestation in the affected limb, while in the extremities (hands and feet) healthy individuals have a maximum difference of $0.4{ }^{\circ} \mathrm{C}$.

Another study of medical thermography in bone lesions of the lower limbs is the research by [26] who analyzed extraction algorithms to determine predictive characteristics for detecting orthopedic trauma abnormality, based on the Euclidean distance, which is the metric distance between two points, between the average pixel and all other image pixels. These authors proposed a Euclidean distance for color image segmentation algorithm based on abnormality of thermographic examinations of arthritis, stress fracture, long bone fracture, and ankle injury. This research demonstrated that the Euclidean distance applied in the thermal images analysis can be a parameter for detecting abnormalities in the lesions studied in apparent bones. These results corroborate our analysis of the 45 thermograms, as thermography allows the exact determination of the fracture site in the images, which facilitates the correct positioning of radiographic image.

Still referring to the applicability of IRT as a supporting tool for screening and early diagnosis in the hospital emergency department, the researchers [27] evaluated thermograms of 110 adult patients of both genders, acquired in foot, leg, thigh, hand, forearm and arm, ankle, knee, wrist, elbow, and shoulder, for the occurrence of acute trauma. The predictive values in the ROls, specifically evaluated in bone fractures, stood higher than $0.9^{\circ} \mathrm{C}$ when comparing the affected to the contralateral limb.

The obtained results present similar characteristics to those found in the investigation presented here, in which thermal differences greater than $0.9^{\circ} \mathrm{C}$ were observed in diagnostics of legs' bone fractures, forearms, hands, feet and ankles, in the comparison between the images of the volunteers' fractured 
portion of the bone and the healthy ones. However, the four evaluated volunteers with clavicles fractures did not present the same thermal difference between the images of the fractured and the healthy portion, denoting the difference of $0.6^{\circ} \mathrm{C}$. It is noteworthy that the investigated clavicular fractures presented mean temperature values higher than $35.0^{\circ} \mathrm{C}$ in all evaluations, with very prominent hot spots on the thermal images, which could be correlated to radiological imaging and anatomical palpation.

The findings of researchers [27], reinforce our main results about the feasibility of thermographic cameras for clinical medical use in the hospital emergency department. Examinations using infrared images as additional diagnostic technology, is sensitive to orthopedic trauma and bone fractures, providing the identification of the anatomic site with abnormal thermal changes to aid the correct diagnosis, avoiding the realization of a second radiological image (due to an error in the positioning of the patient).

\section{Limitations}

Despite the obtained results, this investigation had some limitations regarding the difficulty of acquiring thermal comparative images of the contralateral limb in patients who had entered the hospital on stretchers from the rescue service as victims of traffic accidents. Likewise, in patients with severe pain, the removal of clothing covering the contralateral limb was avoided in respect by medical ethics, with no limb imaging data in the analysis of some patients.

It is important to highlight that the thermal images of clavicle and ankle fractures must be observed with caution, due to the small number of volunteers with fractures in those segments; therefore, the data cannot be extrapolated as thermal reference for clinical diagnostics.

Another relevant limiting factor is the reference studies with medical thermography investigations focused on the assessment of pediatric patients in hospital emergency departments, with few investigation studies being conducted in adult population, making comparative diagnostic analyses difficult.

\section{Conclusion}

Investigation in six body segments of legs, feet, forearm, hands, clavicle, and ankles, of 45 volunteers has demonstrated that infrared imaging is an important complementary diagnostic tool in hospital emergency environments. It may be used as an image modality to support the X-ray gold standard technology for diagnosis and follow-up evaluation of the bone fractures regeneration.

The results show that thermal images indicate the exact location of the traumatic injury, facilitating the correct acquisition of radiological images, as well as the proper positioning of the patient, avoiding repeated exposure to ionizing radiation, with the acquisition of complementary X-rays.

The thermal differences presented in the diagnostics were greater than $0.9^{\circ} \mathrm{C}$ in the ROIs in all volunteers surveyed, being indicative of the presence of bone fracture. 
Clinical information from the diagnostic reference thermal profile applied to orthopedic trauma, combined with data from gold standard exams, emerge as relevant in the applicability of infrared medical image technology in the hospital emergency settings.

\section{Materials And Methods}

\section{Sample}

The sample consisted of 45 adult volunteers, 28 men with a mean age of 34.9 years and 17 women with a mean age of 51.0 years, in emergency care, with clinical suspicion of bone fracture. Images were taken at the emergency department of three hospitals in the city of Curitiba, Brazil, from June 2020 to June 2021.

\section{Material}

The thermal images for bone fractures diagnostics were acquired using a certified medical thermographic camera, Flir model T530 (FLIR® Systems Inc., Wilsonville, Oregon, USA, thermal sensitivity/NETD <40 mK at $30^{\circ} \mathrm{C}\left(42^{\circ}\right.$ lens), $1.31 \mathrm{mrad} /$ pixel, allowing the correlation between the thermal and radiological images acquired on the same date. The environment temperature and humidity of the emergency room was monitored using the Mimipa ${ }^{\circledR}$, model MT-24A device.

\section{Methods}

Medical thermal images were performed according to radiographic positioning protocols, in anteroposterior and oblique views, with the patient lying on hospital stretchers in the orthopedic emergency department of the hospital. Thermograms were obtained in the regions of acute bone fractures in apparent bones, in leg body segments (tibia and fibula bones), hands (phalangeal and metacarpal bones), forearm (radius and ulna bones), clavicle (comprising the entire portion bone), feet (phalangeal, tarsometatarsal and metatarsal bones) and ankle (talus bone and medial and lateral malleolus).

The camera was positioned at a fixed distance of $40 \mathrm{~cm}$ from the bone lesion and kept perpendicular to the assessed body region. Thermographic examinations were performed after the patient acclimatization period to the temperature of the emergency room $21^{\circ} \mathrm{C}$ and $50 \% \mathrm{RH}$, no direct sunlight on the subject, in accordance with the international thermography standard: SS 582-1: 2020 [28]. Data were processed through Flir Tools 6.4 software and exported to be analyzed in the MATLAB R2021a for construction of thermal histograms, Boxplot of the medians and temperature dispersion graphs of the evaluated region. All the patients performed a radiographic examination in the same day as the thermal images.

The regions of interest (ROIs) were defined in the evaluated limbs, centered on the trauma areas, covering the adjacent edges and soft tissues. Thermogram analysis was correlated with radiographic images, with particular attention to the vascular changes in trauma site and adjacent areas. The ROls were defined as 
rectangles, with dimensions adjusted to the evaluated body segment, centered on the highest temperature portion and adjacent edges, as shown in Figure 1.

The thermal images were analyzed by comparing rectangular ROls, with the same size and location, both in the affected limb and in the contralateral and related them to the radiographic images. Thermal data were processed using Flir Tools ${ }^{\circledR} 6.4$ software to calculate the median temperature for each ROI, and the temperature difference from the affected limb to the corresponding contralateral.

\section{List Of Abbreviations}

ROIs: Regions of interest; IR: Infrared thermography; X ray: Radiography image

\section{Declarations}

\section{Ethics approval and consent to participate}

The developed study met the ethical recommendations of Resolution 466/12 and was approved by the Research Ethics Committee of the Federal Technological University of Paraná - UTFPR n ${ }^{\circ} 3014748$, of November 12, 2018 and by the Research Ethics Committee of the Hospital das Clínicas of the Federal University of Paraná (HC/UFPR) - number 3067005 from December 8, 2018.

\section{Consent for publication}

All volunteers were informed about the study, data confidentiality and the importance of the research, then signed an informed consent form.

\section{Availability of data and materials}

All data and images are available to editors.

\section{Competing interests}

The authors declare no conflict of interest.

\section{Funding}

This research was founded by Araucária Foundation and CNPq for scholarships and support for the Coordination for Improvement of Higher Education Personnel - Brazil (CAPES) - Financing Code 001, and Project FCT LAETA-UIDB/50022/2020, UIDP/50022/2020.

\section{Authors' contributions}

Conceptualization, W.A.D.S.; methodology, W.A.D.S and J.M., formal analysis and validation, D.P.C.; investigation, W.A.D.S. and C.J.A.M.; data curation, D.P.C.; writing-original draft preparation, W.A.D.S and 
J.M.; writing-review and editing J.M.; J.F.S. and P.N, funding acquisition, supervision and project administration, P.N.

\section{Acknowledgments}

Thanks to the Municipal Hospital of São José dos Pinhais for participating in the study.

\section{Authors' information}

Not applicable

\section{References}

1. Saraiva JA, de Sousa Cabral TK, Mendes JLCF, dos Santos Souza T, Coelho AG, de Oliveira AM, Torres SG, Cunha FVM: Prevalência de fraturas por acidentes automobilisticos em um hospital público do Piauí. Brazilian Journal of Health Review 2021, 4(2):9430-9444.

2. Schirmer MP: Fraturas por estresse em militares: revisão da literatura fraturas por estresse em militares. 2020.

3. Haluzan D, Davila S, Antabak A, Dobric I, Stipic J, Augustin G, Ehrenfreund T, Prlic I: Thermal changes during healing of distal radius fractures-Preliminary findings. Injury 2015, 46:S103-S106.

4. CORTE ACR, Hernandez AJ: Application of medical infrared thermography to sports medicine. Revista Brasileira de Medicina do Esporte 2016.

5. Lee J, Yao L: Stress fractures: MR imaging. Radiology 1988, 169(1):217-220.

6. Astur DC, Zanatta F, Arliani GG, Moraes ER, Pochini AdC, Ejnisman B: Stress fractures: definition, diagnosis and treatment】. Revista brasileira de ortopedia 2016, 51:03-10.

7. Silva CT, Naveed N, Bokhari S, Baker KE, Staib LH, Ibrahim SM, Muchantef K, Goodman TR: Early assessment of the efficacy of digital infrared thermal imaging in pediatric extremity trauma. Emergency radiology 2012, 19(3):203-209.

8. Reed CL, Saatchi R, Ramlakhan S: Infrared thermal imaging for bone fracture identification and monitoring of fracture healing: A review of the latest developments. 2021.

9. Fazzalari N: Bone fracture and bone fracture repair. Osteoporosis internationa/ 2011, 22(6):20032006.

10. Vardasca R, Ring E, Plassmann P, Jones CD: Thermal symmetry of the upper and lower extremities in healthy subjects. Thermology international 2012, 22(2):53-60.

11. Di Benedetto M, Huston CW, Sharp MW, Jones B: Regional hypothermia in response to minor injury1. American journal of physical medicine \& rehabilitation 1996, 75(4):270-277.

12. Morasiewicz L, Dudek K, Orzechowski W, Kulej M, Stepniewski M: Use of thermography to monitor the bone regenerate during limb lengthening-preliminary communication. Ortopedia, traumatologia, rehabilitacja 2008, 10(3):279-285. 
13. auf der Strasse W, Campos DP, Mendonça CJA, Mendes J, Soni JF, Nohama P: THERMAL PROFILE EVALUATION IN PROXIMAL TIBIAL SHAFT PSEUDARTHROSIS DIAGNOSIS-A CASE STUDY.

14. Prado Campos D, Aguiar Mendonça CJ, Mendes J, Soni JF, Nohama P: Thermal Variations in Osteoporosis After Aclasta ${ }^{\circledR}$ Administration: Case Study. International Journal of Online \& Biomedical Engineering 2020, 16(10).

15. Sanchis-Sánchez E, Vergara-Hernández C, Cibrián RM, Salvador R, Sanchis E, Codoñer-Franch P: Infrared thermal imaging in the diagnosis of musculoskeletal injuries: a systematic review and metaanalysis. American Journal of Roentgenology 2014, 203(4):875-882.

16. Hildebrandt C, Zeilberger K, Ring EFJ, Raschner C: The application of medical infrared thermography in sports medicine. INTECH Open Access Publisher; 2012.

17. de Trotta J, Ulbricht L: Termografia no Diagnóstico Complementar de Doenças Músculo Esqueléticas [Thermography in Complementary Diagnostic of Musculoskeletal Diseases]. Pan American Journal of Medical Thermology 2015, 2(1):7-13.

18. Lahiri B, Bagavathiappan S, Jayakumar T, Philip J: Medical applications of infrared thermography: a review. Infrared Physics \& Technology 2012, 55(4):221-235.

19. Maruyama M, Rhee C, Utsunomiya T, Zhang N, Ueno M, Yao Z, Goodman SB: Modulation of the inflammatory response and bone healing. Frontiers in Endocrinology 2020, 11:386.

20. Sanchis-Sánchez E, Salvador-Palmer R, Codoñer-Franch P, Martín J, Vergara-Hernández C, Blasco J, Ballester E, Sanchis E, González-Peña R, Cibrián R: Infrared thermography is useful for ruling out fractures in paediatric emergencies. European journal of pediatrics 2015, 174(4):493-499.

21. Ring EFJ, Ammer K: Infrared thermal imaging in medicine. Physiological Measurement 2012, 33(3):R33-R46.

22. Ćurković S, Antabak A, Halužan D, Luetić T, Prlić I, Šiško J: Medical thermography (digital infrared thermal imaging-DITI) in paediatric forearm fractures-A pilot study. Injury 2015, 46:S36-S39.

23. Charters A: Detection of distal ulna and radius fractures using thermal imaging as a diagnostic tool on children in the Emergency Department setting. University of Portsmouth; 2014.

24. Snekhalatha $U$, Anburajan M, Teena T, Venkatraman B, Menaka M, Raj B: Thermal image analysis and segmentation of hand in evaluation of rheumatoid arthritis. In 2012 International Conference on Computer Communication and Informatics. IEEE; 2012:1-6.

25. Sousa E, Vardasca R, Teixeira S, Seixas A, Mendes J, Costa-Ferreira A: A review on the application of medical infrared thermal imaging in hands. Infrared Physics \& Technology 2017, 85:315-323.

26. Selvarasu N, Nachiappan A, Nandhitha N: Euclidean distance based color image segmentation of abnormality detection from pseudo color thermographs. International Journal of Computer Theory and Engineering 2010, 2(4):514.

27. Sillero-Quintana M, Fernández-Jaén T, Fernández-Cuevas I, Gómez-Carmona PM, Arnaiz-Lastras J, Pérez M-D, Guillén P: Infrared thermography as a support tool for screening and early diagnosis in emergencies. Journal of Medical Imaging and Health Informatics 2015, 5(6):1223-1228. 
28. Specification for Thermal Imagers for Human Temperature Screening - Implementation Guidelines. In: Singapore Standards Council; SS582: Part 2: 2020.

\section{Figures}

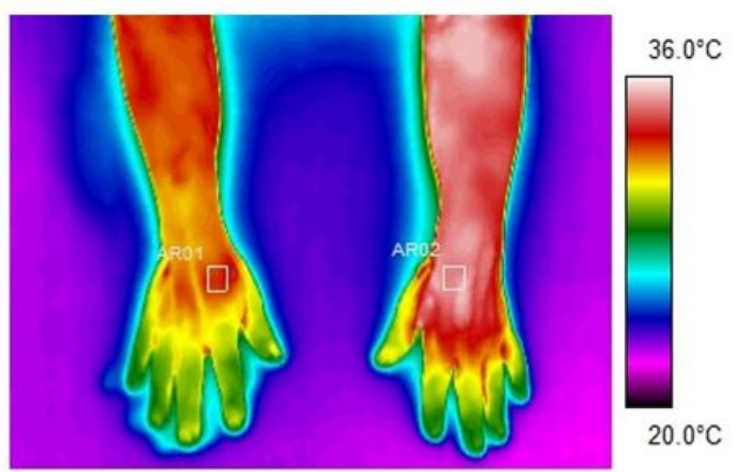

(a)

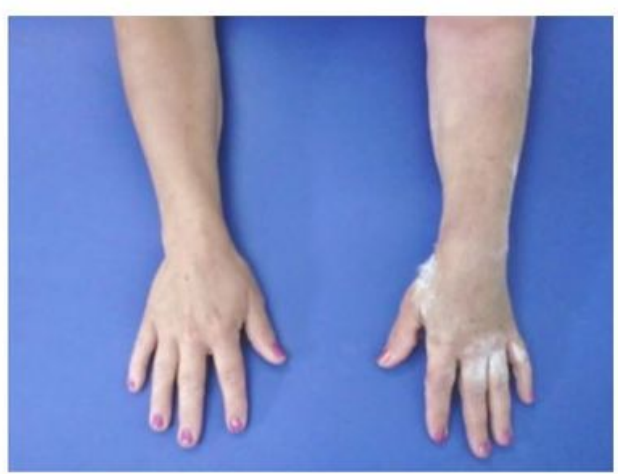

(b)

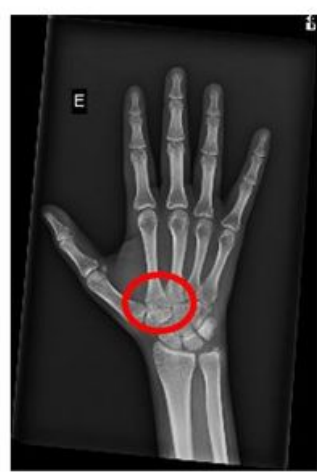

(c)

\section{Figure 1}

(a) shows the thermal image of an acute fracture of the left hand (scaphoid bone) and contralateral limb, with the delimitation of (ROI) defined for comparative analysis; (b) visible image of the evaluated limb; (c) shows the radiographic image of the bone trauma.

\section{Clinical Diagnosis}

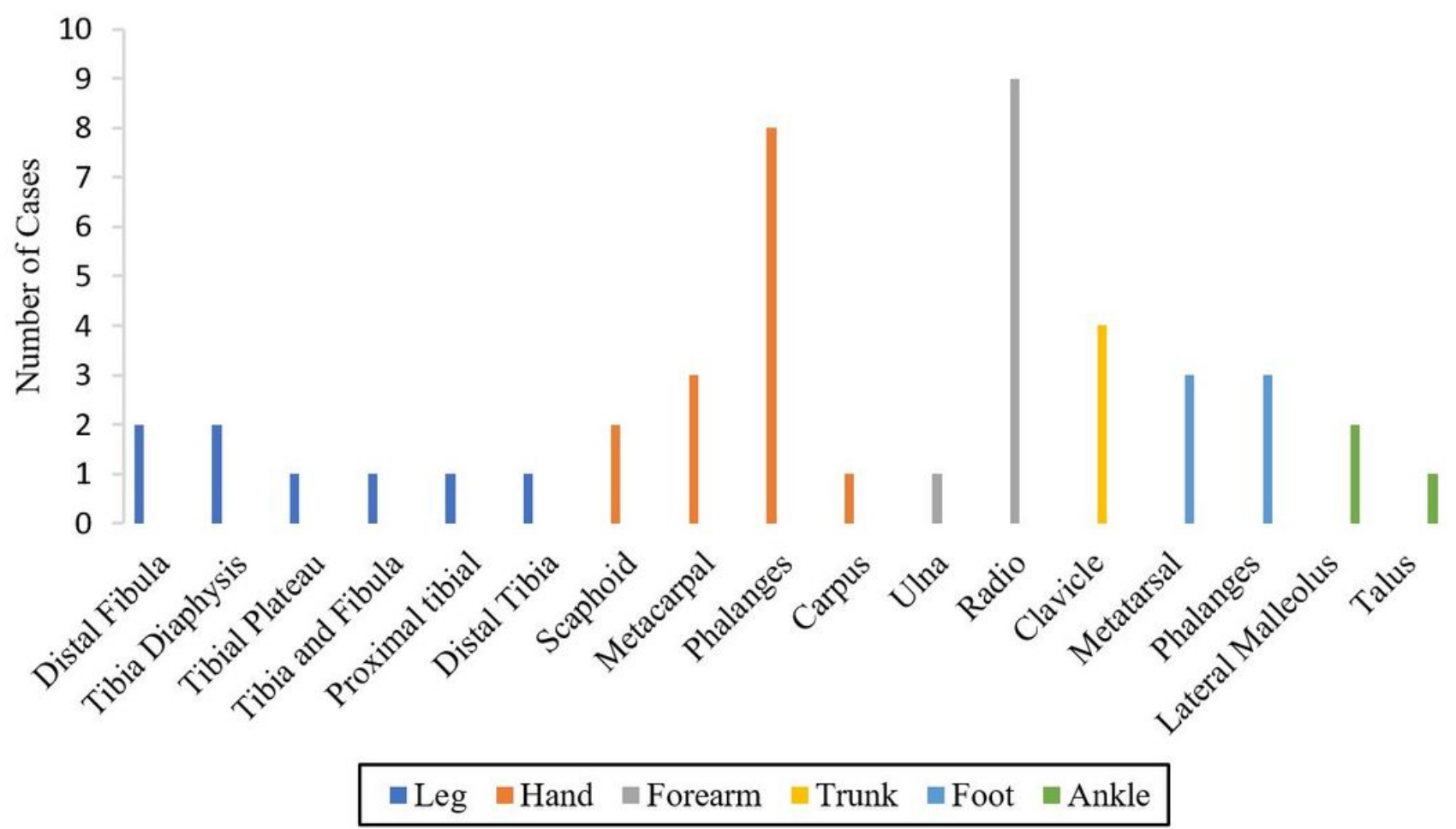


Figure 2

Sample size per body segment diagnosed with bone fracture.

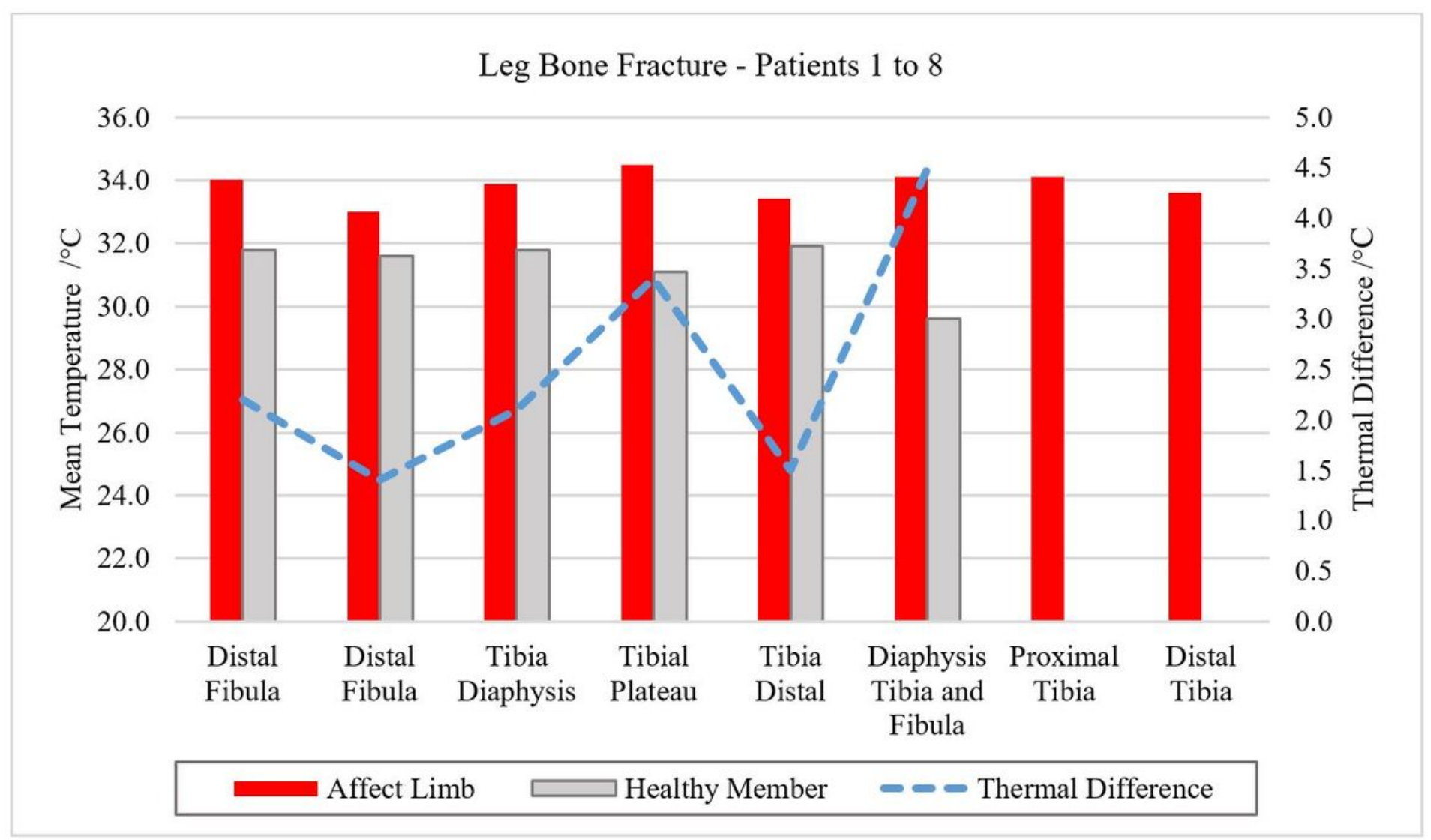

\section{Figure 3}

Mean temperatures in tibial and fibular fractures and contralateral reference limb.

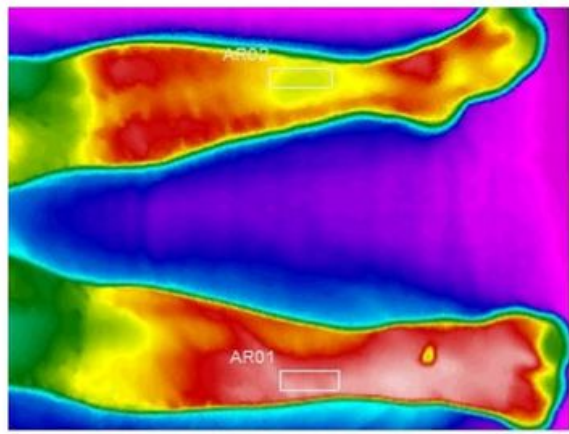

(a)

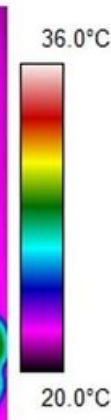

$20.0^{\circ} \mathrm{C}$

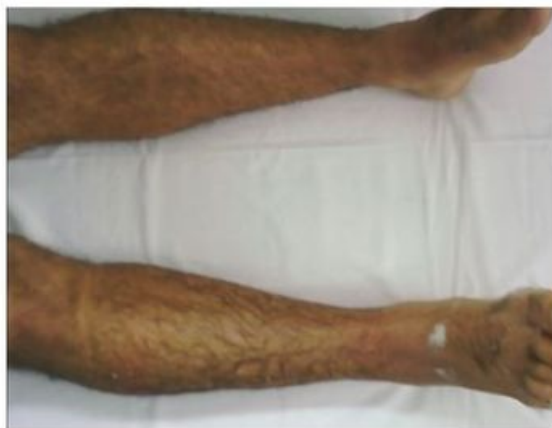

(b)

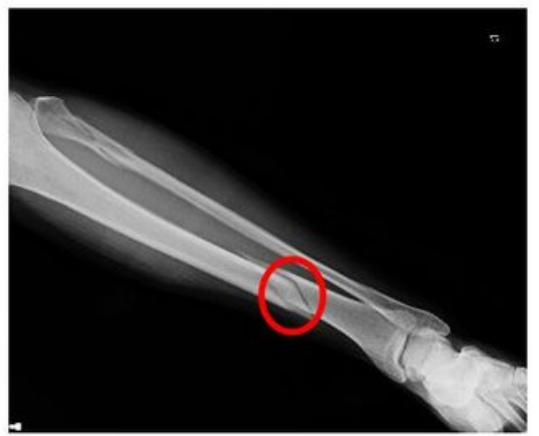

(c)

\section{Figure 4}

(a) Infrared image of the patient's lower limbs with the delimitation of the ROls; (b) Photograph for comparative analysis; (c) Radiographic image. 


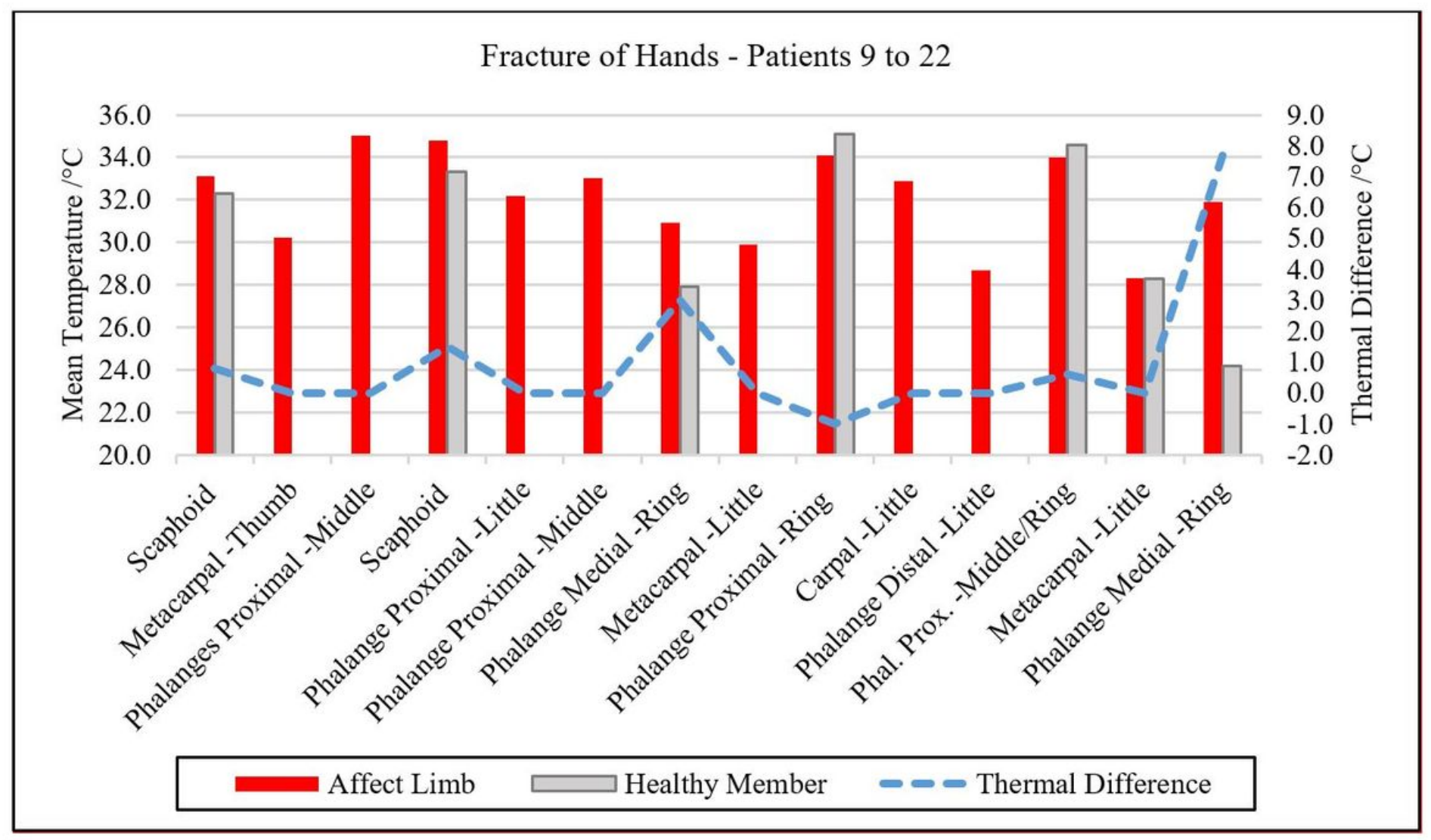

Figure 5

Mean temperature in the ROls corresponding to the fractures and contralateral in bones of the hand.

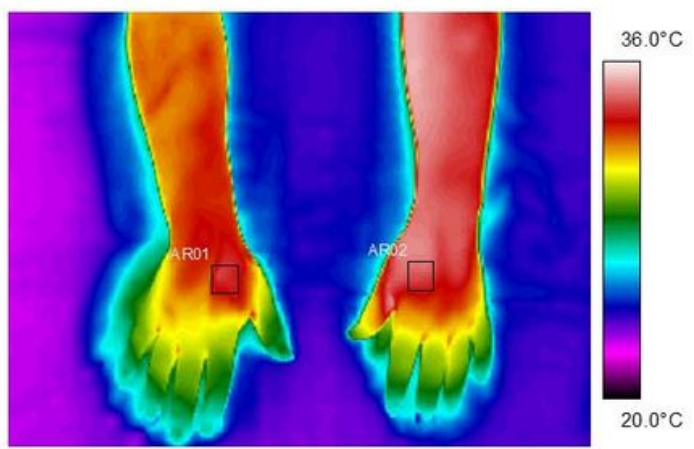

(a)

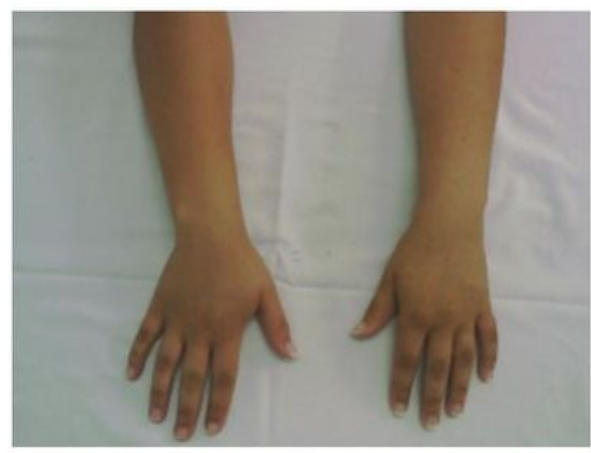

(b)

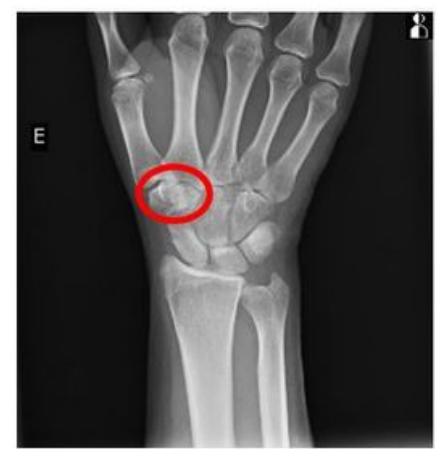

(c)

Figure 6

(a) Shows an infrared thermogram of the volunteer's lower limbs with delimitation of the ROls; (b) a photograph for comparative analysis; (c) shows the correspondent radiography. 
Forearm Fractures - Patients 23 to 32

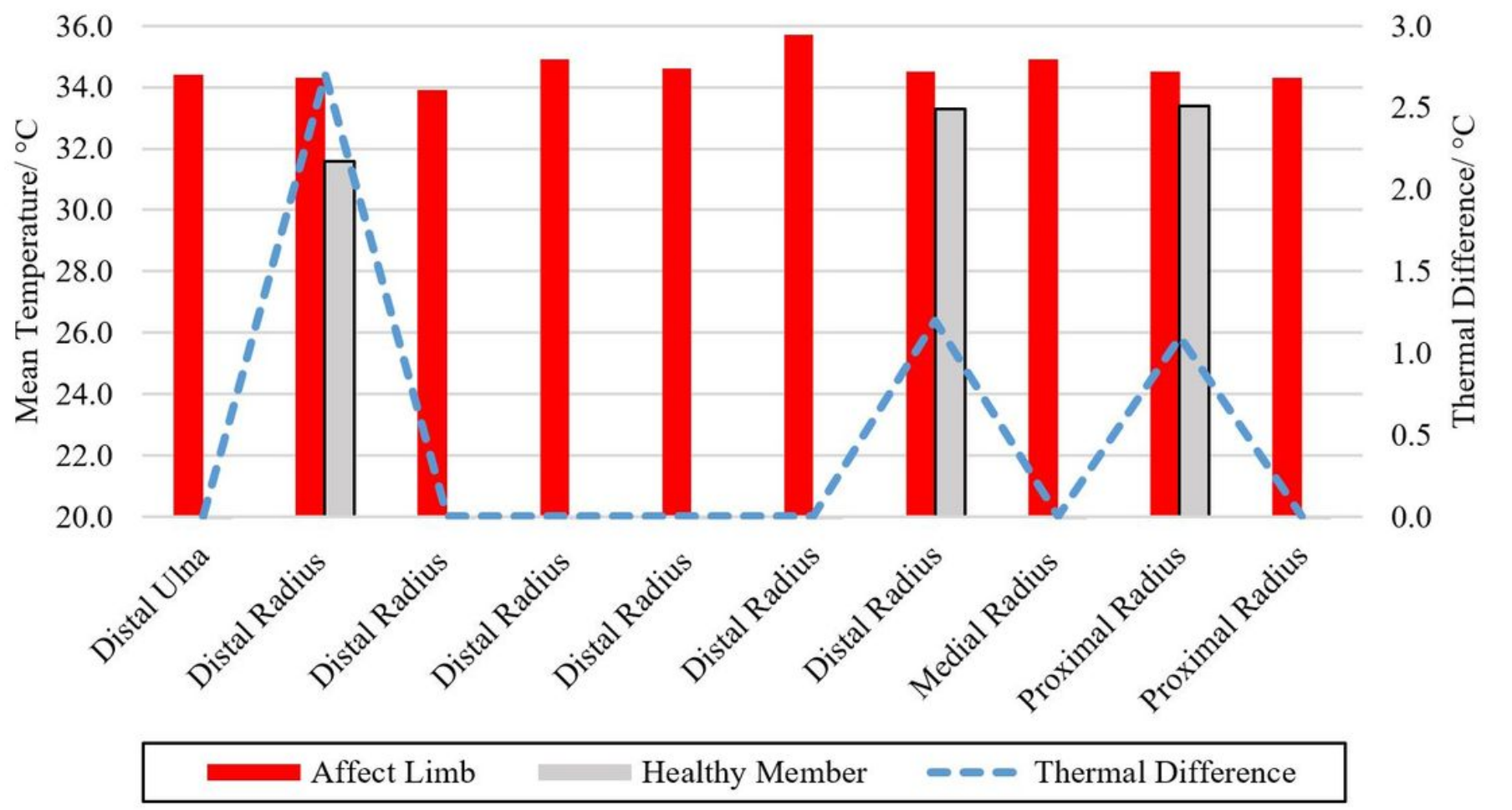

Figure 7

Mean temperature in fractures in the bones of the forearm and contralateral reference limb.

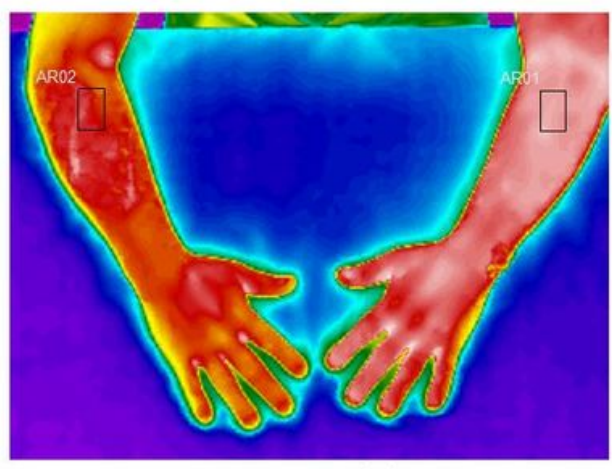

(a)

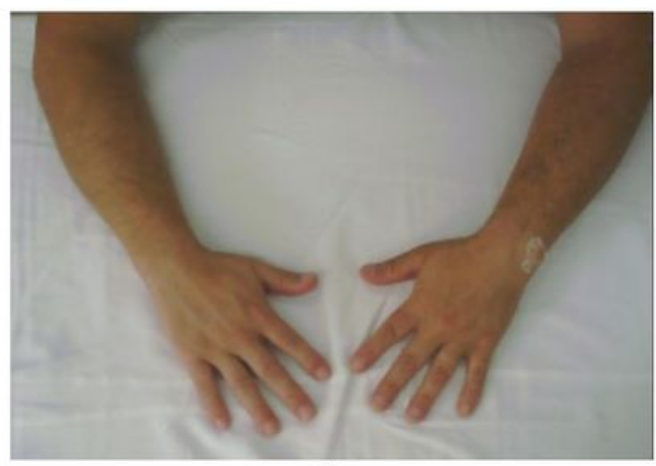

(b)

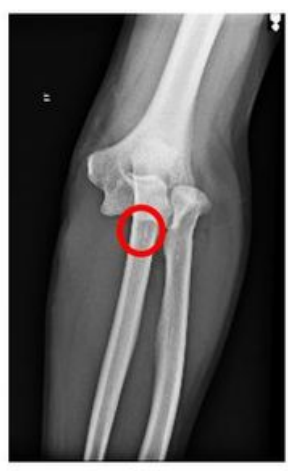

(c)

Figure 8

(a) Infrared image of the volunteer's upper limbs with the delimitation of the ROIs; (b) photograph for comparative analysis; (c) radiographic image for diagnostics correlation. 


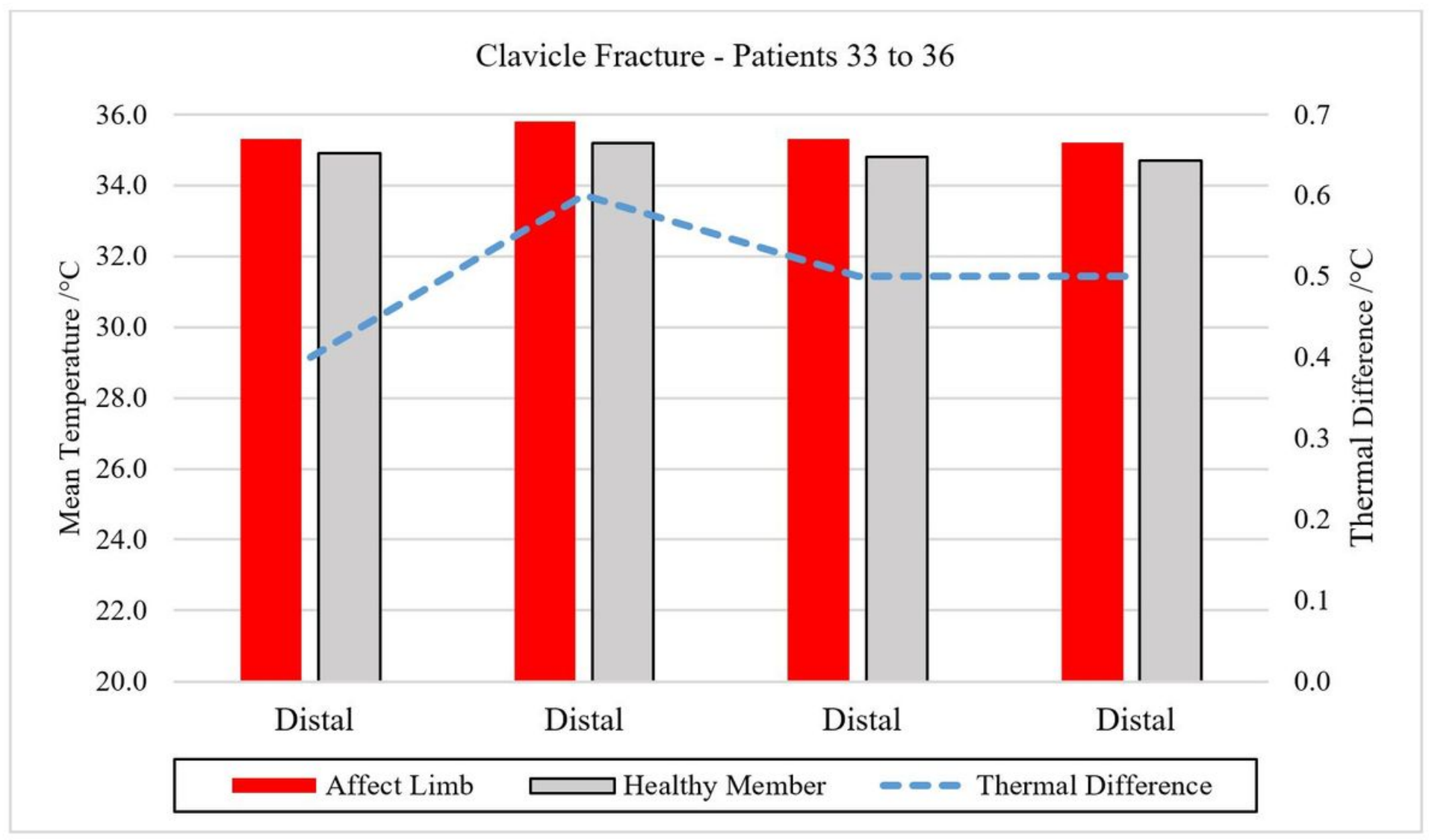

\section{Figure 9}

Mean temperatures in fractures of the clavicle bone and contralateral reference limb.

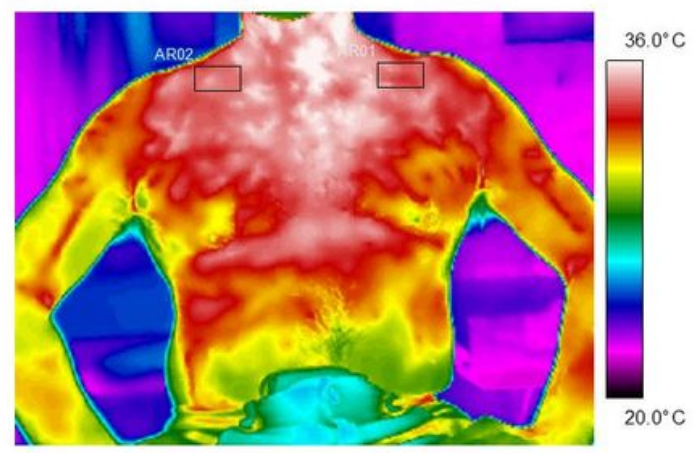

(a)

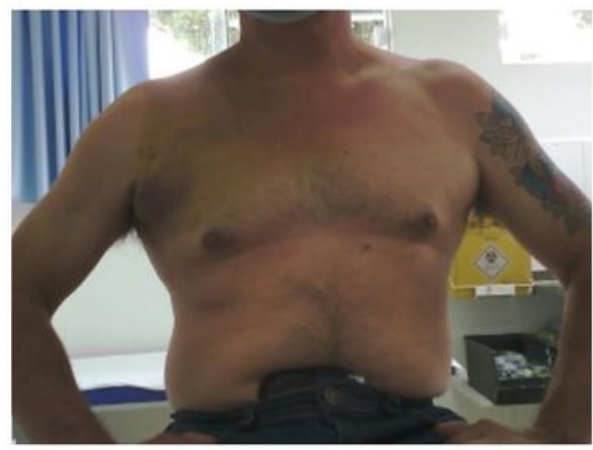

(b)

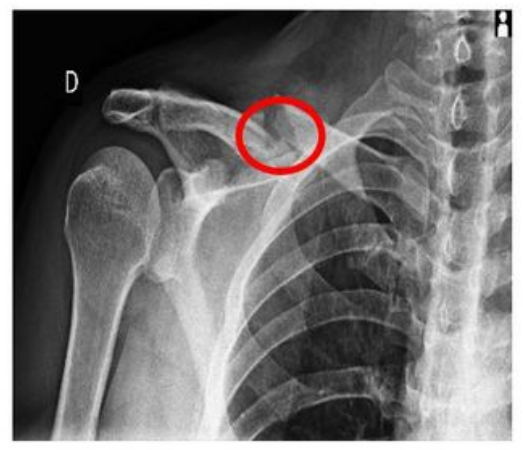

(c)

Figure 10

(a) Infrared image of the volunteer's lower limbs with the delimitation of the ROls; (b) photograph for comparative analysis; (c) Radiographic image for diagnostics correlation. 
Foot Fracture - Patients 37 to 42

36.0

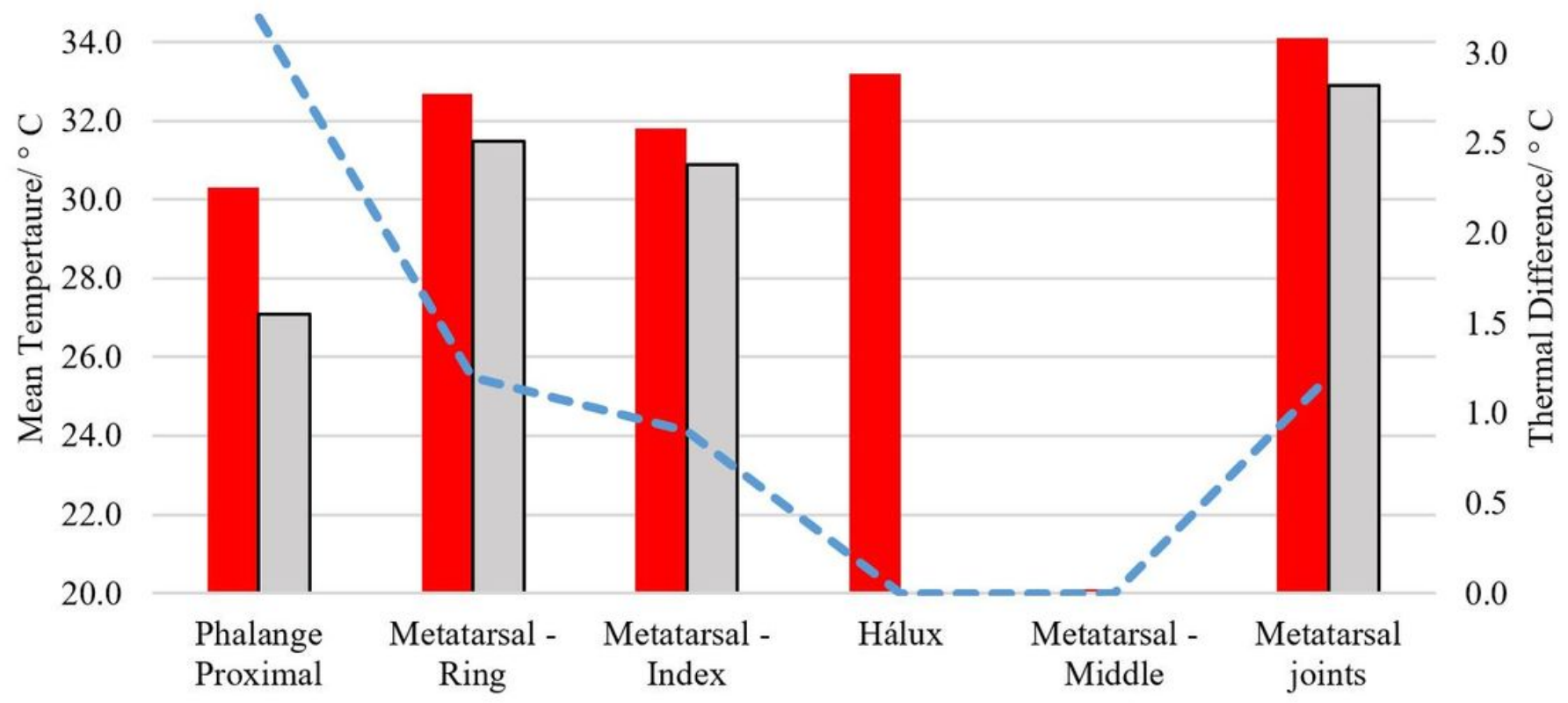

Affect Limb Healthy Member $\quad-\infty$ Thermal Difference

\section{Figure 11}

Mean temperatures in foot fracture bone and contralateral reference limb.

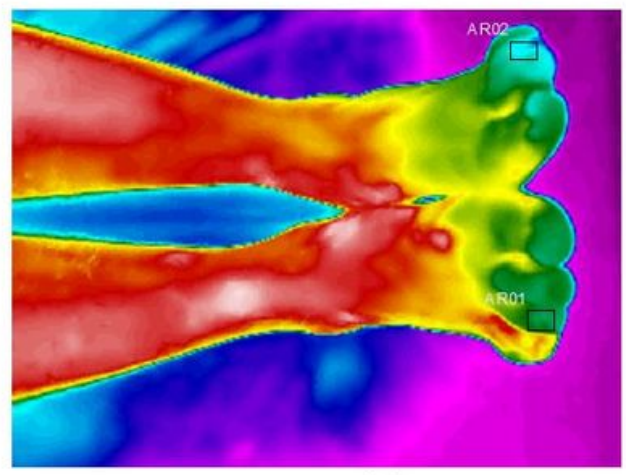

(a)

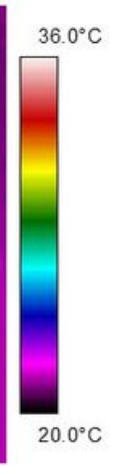

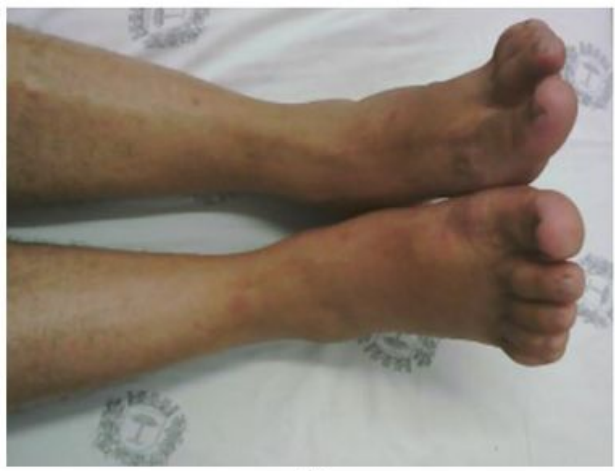

(b)

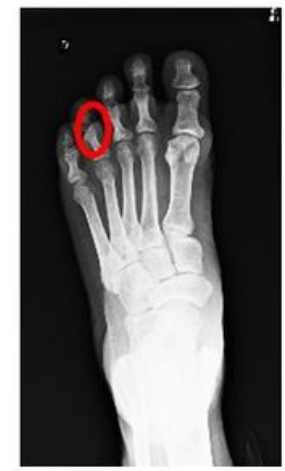

(c)

\section{Figure 12}

(a) Infrared image of the patient's lower limbs with the delimitation of the ROIs; (b) Photograph for comparative analysis; (c) Diagnostic correlation radiographic image. 
Ankle Fracture - Patients 43 to 45

36.0

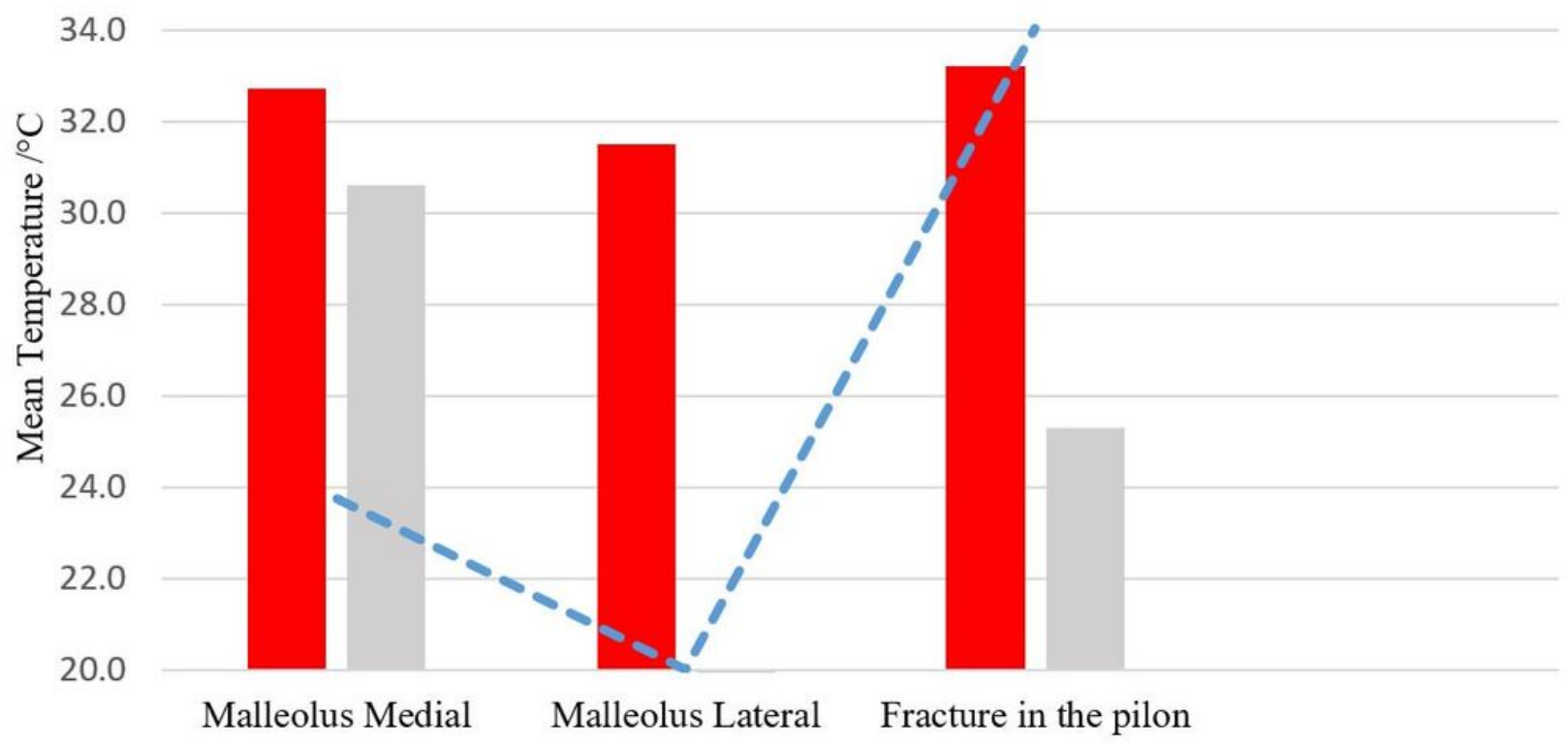

Malleolus Medial Malleolus Lateral Fracture in the pilon

\section{Figure 13}

Mean Temperatures in ankle fracture bone and contralateral reference limb.

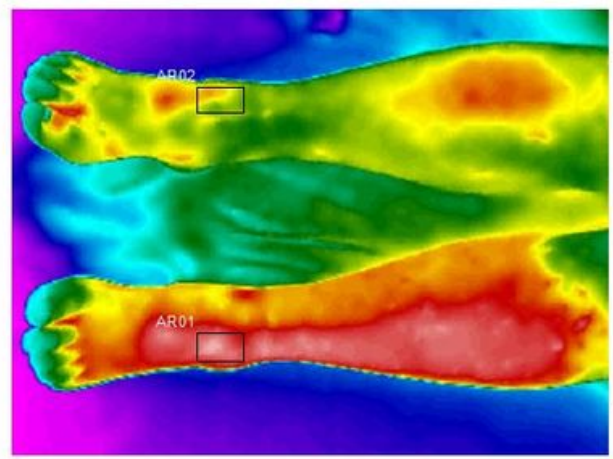

(a)

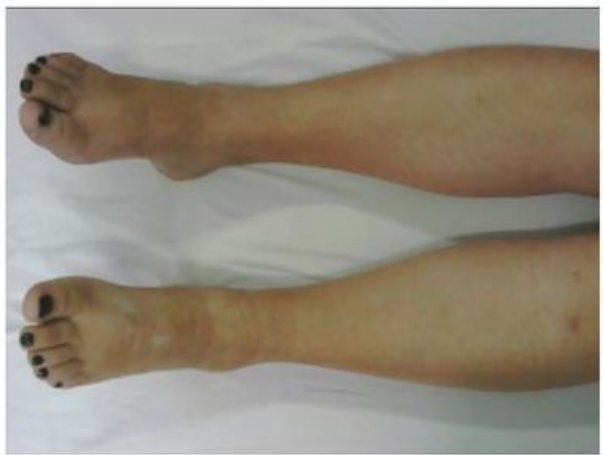

(b)

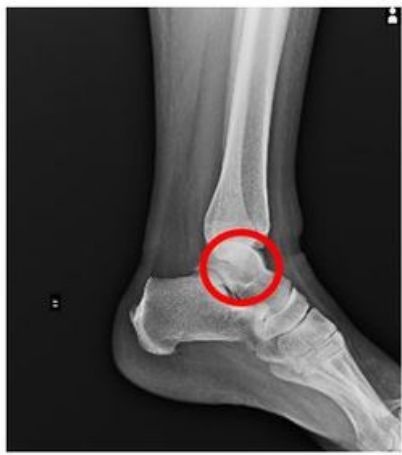

(c)

\section{Figure 14}

(a) Infrared image of the patient's lower limbs with the delimitation of the ROls; (b) Photograph for comparative analysis; (c) Radiographic image for diagnostics correlation. 